\title{
Consideraciones sobre los límites a la libertad de expresión
}

ManUel Alcaraz Ramos

De acuerdo con la doctrina y jurisprudencia ampliamente dominante en EE.UU. y en Europa los Derechos Fundamentales no pueden considerarse absolutos $y$, por lo tanto, encuentran limitaciones tanto en el resto de derechos constitucionalizados como en la estructura interna del propio sistema jurídico-político. En realidad es este un lugar común en la historia de los derechos desde los propios textos de la Revolución Francesa. El principio de relativización de los derechos fundamentales, pues, está claramente formulado. Otra cosa son, desde luego, los problemas prácticos, sobre todo interpretativos, que se plantean en el momento de decidir entre bienes jurídicamente protegidos ante pretensiones legítimas.

Si en algún caso el problema se agudiza es, sin duda, en el de la libertad de expresión y ello debido, en primer lugar, a la propia polisemia de tal derecho. La libertad de expresión se remonta como reivindicación explícita a los tiempos de la Ilustración y en la mejor tradición liberal se acuña conceptual y jurídicamente como derecho subjetivo frente al Estado, lo que era particularmente apropiado en un sistema surgido de las revoluciones contra un Antiguo Régimen que se caracterizaba, entre otras cosas, por un persistente ánimo censor y por las trabas a la iniciativa privada en el rentable negocio de la prensa. Así pues la libertad de expresión decimonónica se plantea ante dodo como un derecho de libertad de imprimir y la menor o mayor amplitud en su regulación constituye un excelente baremo para medir el nivel de dualismo 
liberalismo/conservadurismo y para apreciar las contracciones políticas e ideológicas de la burguesía posrevolucionaria. En este período las limitaciones a la libertad de expresión son fruto habitualmente de restricciones provinientes del puro oportunismo político y sólo tardíamente aparece una legislación sobre lo que hoy denominamos derecho a la propia imagen, que se irá configurando como un derecho autónomo en competencia con los tradicionales derechos de personalidad de la tradición civilística. Hacia finales de siglo se consagran unos modelos clásicos que, en cierta medida, aislan la libertad de expresión de los avatares políticos; máxima expresión y paradigma a imitar será la ley de prensa francesa de 29 de julio de 1881 vigente, en parte, en la actualidad. En dicha ley aparecen también algunos límites relacionados con secreto sumarial y otros aspectos de procesos judiciales. ${ }^{1}$

\section{II}

Con independencia de variaciones doctrinales y jurisprudenciales esta tendencia permanece incólume hasta después de la Segunda Guerra Mundial y, a partir de ahí, la situación cambiará radicalmente sobre todo por dos razones:

-el desarrollo fulminante de unos medios de comunicación poderosos en lo social, cultural, político y económico y difícilmente asimilables a la regulación tradicional de la prensa;

- la conceptualización del Estado del capitalismo tardío como Estado Social.

El juego de ambas circunstancias convierte a la libertad de expresión en un derecho renovado encorsetado en esquemas jurídicos periclitados. En efecto, la larga tradición liberal sobre la libertad de expresión a malas penas puede servir para incidir sobre los problemas actuales de la libertad de información y, más aún, en un esquema transformado en el que el pensamiento del «dejar hacer» cede su puesto, en palabras de Forsthoff, a un "pensamiento interventor» y en el que la pura negatividad de la libertad de expresión -el Estado se abstiene de intervenir - cede su lugar a un derecho que, como todos los derechos fundamentales se convierten ahora en «principios positivos». ${ }^{2}$ 
Surge así el amplio campo del derecho de la información o derecho a la información que, en cierto sentido, opera paradójicamente reduciendo en el significado tradicional: el derecho de expresarse - acción del individuo o de los grupos en que se organiza - cede ante un derecho a ser informado - con lo que esto conlleva de pasividad frente a la anterior actividad-. No profundizamos aquí sobre esta interesante cuestión pero sí hay que advertir sobre la incertidumbre que tales cambios generan en el constitucionalismo actual. Baste señalar, a modo de ejemplo, cómo la cuestión no es ni siquiera abordada formalmente en el constitucionalismo continental del fin de la Segunda Guerra Mundial; el constitucionalismo más reciente ha optado por diversas soluciones. Así, como es sabido, la Constitución Española prefirió unir en el artículo 20 los principios tradicionales sobre la libertad de expresión con otras cuestiones relativas al ámbito al derecho de información e incluso con aspectos particulares como la libertad de cátedra o derechos específicos de los periodistas, con un resultado final que dista mucho de ser satisfactorio desde un punto de vista técnico. En contra, la Constitución portuguesa y la reciente Constitución brasileña han preferido, con desigual fortuna, dividir entre derecho a la libertad de expresión y otros aspectos relacionados con la información; esta división no es baladí pues a nadie se le escapa que una ubicación u otra puede tener una importancia material enorme a la hora de la protección jurisdiccional de los derechos. Finalmente la jurisprudencia anglosajona, especialmente en el caso de EE.UU., ${ }^{3}$ ha seguido un tortuoso camino para afianzar un derecho a la información. Todos estos datos sirven esencialmente para reforzar la idea de la confusión reinante a la hora de delimitar conceptualmente lo que hoy entendemos intuitivamente por libertad de expresión, esa confusión apenas si se desvanece por la acción de una profusa legislación complementaria característica de los Estados en las sociedades desarrolladas. Y en el marco de esa confusión hay que volver a hablar de los límites a la libertad de expresión. Podemos afirmar que a la historicidad de los derechos corresponde una historicidad de sus límites y, en concreto, a las razones que han limitado la libertad de expresión se han sumado otras aumentando así la paradoja a la que antes hacíamos alusión: cuantos más «medios» hay para hacer efectiva la libertad de expresión más limitaciones aparecen. 
Desentrañar la razón de todo ello no es fácil, pondremos un ejemplo que nos permita explicar mejor esa dificultad. Con independencia de las razones de puro oportunismo político a las que antes hacíamos referencia, el límite tradicionalmente más operante han sido los argumentos morales, así los famosos casos contra Flaubert - absuelto- y Baudelaire - parcialmente condenado- supusieron un punto de inflexión en el debate decimonónico sobre la necesidad de censurar o no obras artísticas por razones morales. Que la moralidad es parte de los juegos políticos como demostró la «caza de brujas» y el «código Hays» en EE.UU., es algo tan obvio que no es necesario insistir sobre ello. Ahora bien una identificación entre uso moral de la libertad de expresión y bien público ya plantea más problemas. El famoso juez de la Corte Suprema de EE.UU. Oliver W. Holmes Jr. ofreció un hermoso ejercicio de racionalidad al explicar en el caso «Schenck vs. United States», de 1919, que no puede haber ninguna buena razón para tutelar con el manto de la libertad de expresión al que grita «juego!» en un teatro atestado de público. Pero como siempre es bueno ubicar las opiniones - sobre todo si son brillantes - en su contexto, convendrá recordar que el caso comentado concluyó con la condena de Schenck por enviar cartas a reclutas alistados durante la Primera Guerra Mundial en las que se pedía que rechazaran el servicio militar obligatorio». ${ }^{4}$ Posiblemente desde un punto de vista legal la sentencia fuera irreprochable, pero difícilmente se puede ofrecer un juicio ético sobre la acción encausada sin condenar, por ejemplo, a Bertrand Russell o a Einstein que, a posteriori, ofrecen modelos de comportamiento en situaciones similares de gran valía moral.

Sirva esta pequeña parábola para relativizar los valores éticos que relativizan la libertad de expresión. En cualquier caso no quisiéramos ser injustos con el juez Holmes, que, con motivo del caso comentado formuló su doctrina del «riesgo claro e inminente», progresista para su época y que, de hecho, no se generalizó en la jurisprudencia norteamericana hasta 1937: «sólo aquellas formas de expresión que conlleven un riesgo claro e inminente de causar un comportamiento materialmente violento y dañino, y que no puede ser contrarrestadas a tiempo con más expresión, discusión o debate, pueden ser objeto de represión legal». 5 
En cualquier caso tal declaración, en la mejor herencia jeffersoniana, no ha podido quedar incólume, por ingenua, ante los nuevos retos de la sociedad de la información. Como hemos indicado al principio las teorías vigentes en la actualidad se centran en el relativismo o «balance de intereses» que, sin duda, ofrece, al menos, la ventaja de dejar puertas abiertas a una situación informativa muy fluctuante. Esta posición ha sido la dominante en el Tribunal Constitucional español. ${ }^{6}$

\section{III}

Sin embargo, por flexible que se presente el principio de «balance de intereses» hay siempre, en el esquema del Estado de Derecho, que evaluar los intereses jurídicamente protegidos, $o$, dicho de otra manera, la pervivencia del Estado de Derecho exige una constitucionalización previa de los intereses a contrapesar con el acto de expresión que se quiere limitar. Acudiendo al Derecho Constitucional español recordemos lo afirmado por el Tribunal Constitucional en sentencia de 29 de enero de 1982: «Todo derecho tiene sus límites que (...) establece la Constitución, por sí misma en algunas ocasiones, mientras que en otras el límite deriva de una manera mediata o indirecta de tal norma, en cuanto ha de justificarse por la necesidad de proteger o preservar no sólo otros derechos constitucionales sino también otros bienes constitucionalmente protegidos». En este sentido, el profesor Carrillo, en la mejor monografía publicada sobre los límites a la libertad de expresión en la Constitución Española, ${ }^{7}$ hace una afirmación que compartimos: «no son deducibles, en principio, más límites a la libertad de expresión que aquellos que el artículo 20.4. especifica y los que se derivan de la ratificación por España del Convenio de Roma». Esta afirmación, en cualquier caso, requiere dos matices:

1.-Nos referimos a la libertad de expresión, ahora, desde un punto de vista formal, sin analizar, por ejemplo, el alcance del artículo 9.2 C.E. sobre esta materia y que implicaría para los poderes públicos remover los obstáculos que dificultan una dimensión igualitoria de la libertad de expresión, lo que nos llevaría a adentrarnos en una maraña de situaciones que van desde las televisiones privadas a las radios libres, pasando por el derecho de antena. 
2.-Ciertas limitaciones reales a la libertad de expresión pueden encontrar su fundamentación en ese artículo 20.4 o en el Convenio de Roma, pero a condición de interpretar muy extensivamente los derechos del Título I, por ejemplo en lo relativo a aspectos regulados en la legislación de defensa o de emergencia.

\section{IV}

Dicho eso, partiremos de esos dos polos - artículo 20.4. y Convenio de Roma-, para tratar de ofrecer una tipología - coincidente, por otra parte, con la mayoría del derecho comparado- de los límites de expresión.'

1.-Límites basados en la protección de derechos inherentes a la personalidad. En especial los derechos a la imagen, honor e intimidad ${ }^{8}$ y también normas obligatorias sobre secreto profesional.

2.-Límites que afectan para la seguridad nacional e integrado territorial. En especial las legislaciones dedicadas a secretos de Estado.

3. - Límites derivados de la acción interventora del Estado social de derecho:

3.1.-Regímenes de autorización previa para la concesión de licencias para la actuación de empresas informativas y culturales. ${ }^{9}$

3.2.-Protección de ciertos colectivos sociales. En especial la infancia y la juventud.

3.3.-Protección de la salud. En especial con prohibiciones en materia publicitaria - tabaco, alcohol, medicamentos.

4. - Límites derivados de requisitos para el buen funcionamiento de la administración de justicia. En especial lo referente al secreto sumarial. En el mismo sentido: límites a la difusión de actos parlamentarios.

5.-Límites derivados de la seguridad y el orden público.

5.1.-Legislación ordinaria que previene la comisión de delitos.

5.2.-Legislación especial antiterrorista. 
6.-Límites derivados de derechos humanitarios.

6.1.-Prevención de la guerra y el genocidio.

6.2.-Prevención del racismo y otros tipos de discriminación.

Los puntos $1,2,3,4$ y 5.1 podemos clasificarlos de clásicos, unos porque contribuyen a asegurar el funcionamiento de los instrumentos de actuación del Estado y otros porque son herederos de la fuerte tradición privatista de la burguesía decimonónica que, en algunos casos, asimila valores propios de la nobleza dominante en el Antiguo Régimen. Más interés, desde el punto de vista de la novedad, tienen los puntos 5.2 y 6 y a ellos, de forma conjunta, vamos a dedicar los siguientes párrafos.

No pretendemos hacer un estudio pormenorizado de las implicaciones de la reciente legislación antiterrorista europea, legislación que, como ha demostrado López Garrido ${ }^{10}$ ha trastocado algunos de los principos constitucionales, penales y jurisdiccionales más caros al pensamiento occidental del Estado de Derecho, sobre todo desde el momento en que «el concepto de delito terrorista ha terminado por acoger como un elemento fundamental la idea de "fin" de la conducta. Y, a pesar de la proclamada intención de reducir el delito terrorista a la categoría de delito común, su definición legal ha necesitado incluir el sentido político de la acción reprimida penalmente». Dentro de las alteraciones experimentadas en la tipificación y/o el agravamiento de penas a actuaciones derivadas de actos de expresión de pensamientos ha sido el más relevante junto con actos tendentes a penar acciones contra la vida, la integridad física o la libertad de las personas. Ello es así por el carácter «propagandístico» esencial del acto terrorista, lo que ha planteado la duda misma sobre la conveniencia de publicar información -entiéndase «aséptica»- de los actos terroristas y que ha dado lugar al intento del gobierno conservador británico de imponer normas censoras y redundantes y, por lo general, infructuosos debates sobre deontología periodística. Sin entrar en esta cuestión sí hay que señalar algunas mutaciones legales significativas que, en muchos casos, convierten a la expresión del pensamiento político en delito o lo caracterizan como inducción. 
En la República Federal Alemana la reforma del Código Penal de 18-8-1974 introdujo, en el artículo 129.a), la pena de prisión de 6 meses a 5 años para quien fundare una asociación terrorista, incluyendo en los supuestos tipificados a quien «la apoye o haga proselitismo a favor de ella». Esta reforma era coherente con el camino abierto por la enmienda 17 a la Ley Fundamental de Bonn de 24-6-1968, sobre su artículo 5, que en lo referente a la libertad de expresión, investigación y cátedra preveía que tales derechos se limitaran por una ley general bajo el principio de la «lealtad a la Constitución». " Ello daría lugar a la famosa «resolución sobre los radicales», firmada en junio de 1972 por la Conferencia de los Presidentes de los Länders y el Canciller Federal Brandt, publicada como decreto y que afectó a tres millones de funcionarios a los que se exigía una "actitud de fidelidad» a la Constitución y a su «orden fundamental liberal democrático»; pese a ver afirmada la constitucionalidad de tal decreto por el Tribunal Constitucional en junio de 1975, fue sustituido por otro decreto del 16-6-1976 que adoptó el principio «de examen de la lealtad a la Constitución para los candidatos a la función pública». El Tribunal Constitucional, en el asunto Empell, amplió aún más la interdicción profesional por razones políticas en octubre de 1977. Finalmente el 17-1-1978 el gobierno adoptó un acuerdo para precisar con más detalle el significado del principio de «fidelidad a la Constitución» («Verfassungstreue»).

Paralelamente a este proceso en enero de 1976 se aprobó por unanimidad la «ley para la protección de la paz conciudadana», que modificaba oțros artículos del Código Penal, así el artículo 88.a) pasó a imponer penas de hasta tres años para el que difundiera escritos que supongan amenazas a la paz pública o que impliquen aprobación de «acciones contra la existencia y la seguridad de la República Federal Alemana o de sus principios constitucionales». Por otra parte el artículo 130.a), pasaba a considerar delito a la divulgación de escritos que contengan «instrucciones» para acciones violentas, permitiendo en su evaluación y penalización un amplio margen a la interpretación jurisprudencial. Como vemos, el sistema punitivo en la República Federal Alemana se ha visto muy reforzado y, sin adelantar conclusiones, al menos puede evidenciarse cómo en nombre de la defensa del «orden liberal» se asesta un duro golpe a la tradición liberal y se debilita extraordinariamente 
la estructura conceptual del Estado democrático de derecho, sobre todo por las restricciones impuestas a los posibles funcionarios que, no lo olvidemos, incluye a los profesionales públicos de la enseñanza.

España, por su parte, se sumó a la ola de la legislación antiterrorista con la Ley Orgánica 9/1984 de 26 de diciembre contra la actuación de bandas armadas y elementos terroristas y de desarrollo del artículo 55.2 de la Constitución, que, posiblemente, sea la ley de este tipo, en el contexto europeo que incluye más limitaciones a la libertad de expresión de «apología» de delitos contemplados en la ley, para tal tipo prevé pena de prisión menor y multa de 150.000 a 750.000 pesetas. El número 2 del citado artículo se dedica a precisar, de forma extremadamente ambigua, lo que se entenderá por «apología»:

-alabanza o aprobación en público de los hechos delictivos comprendidos en la ley;

- apoyo o ensalzamiento de la rebelión o actividades propias de organizaciones terroristas, armadas o rebeldes «o de los hechos y efemérides de sus miembros mediante la publicación y difusión en los medios de comunicación social de artículos de opinión, reportajes informativos, composiciones gráficas, comunicados y, en general, cualquier otro modo en que se materialice la difusión»;

- apoyo o adhesión «mediante discursos, soflamas u ostentación de pancartas, que se produjeran durante la celebración de concentraciones en las vías urbanas u otros lugares abiertos al público».

Como puede verse, de un cumplimiento estricto de la ley se derivaría la práctica imposibilidad de informar y opinar sobre actos terroristas.

El artículo 21, por su parte, preveía el cierre de medios informativos que intervinieran en la apología de forma grave o habitual. Sin embargo el Tribunal Constitucional, tras el recurso presentado por los Parlamentos vasco y catalán, declaró inconstitucional este artículo $21-\mathrm{y}$ otros- en la sentencia 199/1987 de 16 de diciembre.

El caso italiano ofrece mayores peculiaridades. El punto de referencia hay que tomarlo en la Ley de 22-5-1975 sobre la tutela del orden público ("Ley Reale»). ${ }^{12}$ En su artículo 10 preveía penas de 6 meses a 2 años, privación de derechos y multa a «quien haga propaganda para 
la constitución de una asociación, movimiento o grupo que atente contra el orden público según lo define el artículo 1 de la misma ley». A continuación fija las mismas penas «a quien públicamente exalte exponentes, principios, hechos o métodos del fascismo o sus fines antidemocráticos, o bien, ideas o métodos racistas». Para ambas circunstancias se prevé un agravamiento de las penas si se utiliza «la imprenta». El artículo 11 castiga con reclusión de hasta tres años y multa «a quien participando en reuniones públicas, realice manifestaciones usuales del disuelto partido fascista o de organizaciones nazis». Por otra parte el artículo 13 también penaliza a los que financien las actividades anteriormente descritas incluyendo los gastos de imprenta. Como vemos la ley italiana introduce una originalidad motivada seguramente por la propia historia del país: junto a la tipificación y penalización de los actos terrorristas genéricamente considerados se prevén supuestos específicos contra el fascismo, el nazismo y contra el racismo, encontrándonos, en este último caso, ante un supuesto de límite derivados de derechos humanitarios.

En realidad ya se puede encontrar un precedente aún más claro en el derecho de prensa francés. En diversas normas se condena la apología del delito, a veces, como ha señalado algún autor, con difíciles «fronteras»; ${ }^{13}$ pero, además, la Ley de 1-7-1972 tipificó y penalizó la provocación a la discriminación, el odio racial y la difamación a causa de la etnia, nación o religión. Antes de volver a los problemas de interpretación jurisprudencial a que esta norma ha dado lugar conviene hacer algunas precisiones sobre la aparición y virtualidad jurídica de estas limitaciones establecidas por razones humanitarias.

\section{VI}

Históricamente se pueden rastrear intervenciones del poder en un sentido similar - salvando las enormes distancias jurídico-políticasante los preocupantes brotes de antijudaismo en el final de la Edad Media y durante el Renacimiento. En la provocación de esas manifestaciones antisemitas ejercían un papel importante el teatro religioso y las predicaciones masivas. Se tiene constancia de prohibición de representa- 
ciones en numerosas ocasiones o, al menos, de la supresión de las escenas antijudías, estando bien documentada, por ejemplo, la supresión de estas escenas en 1338 en Friburgo de Brisgovia; en otros casos, por ejemplo en Frankfurt en 1469 se ordenaba la protección de barrios judíos durante las representaciones de un «misterio». Igualmente, en junio de 1348, Pedro IV de Aragón comunicó a los vicarios episcopales y al capítulo catedralicio de Barcelona el deber de calmar a los predicadores antijudíos; y Fernando I de Aragón dictó medidas contra algunos sermones que hoy consideraríamos racistas de Vicent Ferrer del que, sin embargo, era personalmente un gran admirador. ${ }^{14}$

En todos estos antecedentes lo que se perseguía, evidentemente, es asegurar la estabilidad y la paz social, tanto proveyendo altercados y disturbios como buscando el mantenimiento de un «statu quo» económico y político. Algo similar, si se permite la comparación, sucede con la unión que vemos entre reclamaciones humanitarias y legislación antiterrorista en nuestra época. El derecho interno objetiviza, politiza, las reclamaciones ideológicas herederas de «Derecho de Gentes» que, tras los horrores de la Segunda Guerra Mundial, florecen en Tratados Internacionales.

Sin ánimo de ofrecer una guía completa de los límites por razones humanitarias en el derecho Internacional sí que intentaremos ofrecer una visión de conjunto sobre la cuestión. Quizás la primera alusión la encontramos en el Convenio sobre la prevención y castigo del delito de genocidio, de 9 de diciembre de 1948, propiciada por la ONU, que en el artículo III,c) declara como acción punible «la instigación directa y pública a cometer genocidio», preveyendo para esta acción, y para otras descritas en el mismo artículo, la retroactividad en el artículo IV. Por su parte, la Convención Internacional sobre la eliminación de todas las formas de discriminación racial, de 21 de diciembre de 1965, también adoptada en el marco de la ONU, dedica un largo artículo $4 .^{\circ}$ a la condena de «toda la propaganda y todas las organizaciones» que se inspiren en o difundan el racismo o la discriminación, los Estados Partes, así «se comprometen a tomar medidas inmediatas y positivas a eliminar toda incitación a tal discriminación o actos...»; en concreto los firmantes se comprometen: «a) Declararán como acto punible, conforme 
a la ley, toda difusión de ideas basadas en la superioridad o en el odio racial, toda incitación a la discriminación racial...» y «b) Declararán ilegales y prohibirán las organizaciones, así como las actividades organizadas de propaganda que promuevan la discriminación racial e inciten a ella, y reconocerán que la participación en tales organizaciones o en tales actividades constituye un delito penado por la ley».

En los textos internacionales de carácter más global hay que referirse forzosamente al Pacto Internacional de Derechos Civiles y Políticos, de 19 de diciembre de 1966, de nuevo acordado en la ONU: tras asegurar el artículo 19 la libertad de expresión limitado en su número 3 por el respeto y reputación de los demás, por la protección de la seguridad nacional, el orden público, la salud y la moral públicas, dedica el artículo 20 a establecer límites basados en las razones humanitarias que venimos comentando: «1. Toda propaganda en favor de la guerra estará prohibida por la ley. 2. Toda apología del odio nacional, racial o religioso que constituya incitación a la discriminación, la hostilidad o la violencia estará prohibida por la ley».

En cuanto a los textos regionales hay que advertir cómo el Derecho europeo no ha insistido especialmente en estas cuestiones, posiblemente porque los Estados europeos eran firmantes de los acuerdos de la ONU, todo ello con independencia de las limitaciones genéricas establecidas en el Convenio de Roma a las que ya aludimos. Puestos a elegir un ejemplo de acuerdo regional fuera de Europa podemos referirnos a la Convención Americana sobre Derechos Humanos o «Pacto de San José de Costa Rica» adoptado el 22 de noviembre de 1969, en esta Convención se garantiza la libertad de expresión genéricamente por el artículo 13.1 en los números siguientes se alude a las limitaciones clásicas y en el párrafo 5 se declara: «Estará prohibida por la ley toda propaganda en favor de la guerra y toda apología del odio nacional, racial o religioso que constituyan incitaciones a la violencia o cualquier otra acción ilegal similar contra cualquier persona o grupo de personas, por ningún motivo, inclusive los de raza, color, religión, idioma u origen nacional».

Como vemos en el Derecho Internacional vigente existe una amplia panoplia de instrumentos jurídicos encaminados a asegurar limitacio- 
nes, por razones humanitarias, a la libertad de expresión. Sin embargo la virtualidad de su aplicación encuentra muchas dificultades, algunas propias de la aplicación de cualquier norma internacional y otras derivadas de la propia especifidad de estos preceptos. En efecto, sin necesidad de insistir sobre la práctica imposibilidad de imponer a muchos Estados, con independencia de ser o no firmantes de los acuerdos o pactos, el cumplimiento eficaz de las normas, a nadie se le escapan los problemas de traslación a la ordenación jurídica interna de preceptos del tipo que venimos comentando, ${ }^{15}$ sobre todo en lo que implica regulación penal. Es por ello significativo que, precisamente, en varios países europeos se haya aprovechado la legislación antiterrorista para introducir estos límites, en un intento de dulcificar así las aristas más duras de una plasmación jurídica tan represiva; por otra parte la concepción finalista apuntada en las leyes antiterroristas desvirtúa en buena medida la intención de los pactos y convenios internacionales.

Pero aún queda una última dificultad en la aplicación de estas normas derivada de su interpretación jurisprudencial. Es interesante la polémica desatada en Francia y que quizás encuentre su mejor reflejo en el contenido de la sentencia del Tribunal Correccional de París de 6 de diciembre de $1984 ;{ }^{16}$ el elemento en discusión esencial radica en el hecho de si hay que interpretar las prohibiciones contra la difamación racial o contra la incitación a la discriminación como delitos autónomos, es decir, con independencia de que causen o no situaciones reales de discriminación, odio o venganza racial. La polémica sigue y seguirá abierta, aunque, al menos en la jurisprudencia de la Corte de Casación parece triunfar la tesis de un delito autónomo de provocación. Pero la solución no es fácil pues, con independencia de la repugnancia que puedan causar las opiniones enjuiciables, siempre se bordea el espinoso tema de salvaguardar el contenido esencial del derecho a la libertad de expresión, a la vez que se pueden crear precedentes aplicables en el enjuiciamiento de opiniones que no serían punibles de acuerdo con las normas internacionales pero sí con otras normas internas y aquí, de nuevo, volvemos a encontrarnos con las leyes antiterroristas. 
Extraer conclusiones definitivas sería demasiado ambicioso, pero sí pueden ensayarse algunas conclusiones provisionales:

1.-La libertad de expresión está constitucionalizada e interpretada por la jurisprudencia y por la doctrina dominante tanto como un derecho subjetivo como una función social, pero también hay que interpretarla como cumplidora de una función política fundamental en las sociedades desarrolladas, esencialmente porque permite circular información, renovar el consenso e integrar controladamente las críticas al sistema; desde este punto de vista la libertad de expresión, junto con otros derechos fundamentales, contribuye decisivamente a asegurar la legitimidad y la estabilidad del sistema.

2.-Desde esta perspectiva los límites a la libertad de expresión buscan, políticamente, prohibir intervenciones que rebasan dicha función legitimadora. Puede interpretarse así históricamente la evolución experimentada en los límites; paulatina y comparativamente pierden pero las limitaciones derivadas de los derechos privados - que había sido un instrumento esencial en la consolidación político-ideológica de la burguesía - en favor de límites más políticos.

3.- En ese panorama se refuerza cada vez más los límites derivados de la seguridad y el orden - leyes antiterroristas - y de las normas humanitarias de origen internacional. Con independencia de la necesidad de arbitrar políticas penales que atajen un fenómeno como el terrorismo, en el campo de la libertad de expresión las medidas adoptadas se revelan habitualmente como desproporcionadas, lo que puede explicarse por el carácter político de la apreciación de los delitos terroristas -aunque los actos típicamente terroristas: atentados, homicidios, lesiones, secuestros... sean actos tipificados como delitos comunes-: el sujeto pasivo último de todo acto terrorista es el Estado y toda opinión favorable al terrorismo - con todo su cinismo y desfachatez- supone un peligro a la legitimidad imperante, aunque no impliquen una legitimidad alternativa.

4.-Pero la represión antiterrorista también reporta unos costes en legitimidad, ese déficit se ha tratado de cubrir con el recurso a los lími- 
tes derivados de derechos humanitarios, con la consecuente e interesada confusión jurídica, por lo que, «de lege ferenda» sería deseable:

- separación de las normas antiterrorista de las basadas en derechos humanitarios, aunque, en algunos casos, pudieran concurrir ambos aspectos;

-regulación en los ordenamientos internos con la máxima precisión posible de los tipos penales derivados de la aplicación de las limitaciones a la libertad de expresión contenidas en los acuerdos y pactos internacionales de carácter humanitario.

\section{N O T A S :}

1. Ph. Bilger y B. Prevost. «Le droit de la presse». PUF, París, 1989. P. 5 y ss.

2. F. Forsthoff. «El Estado en la sociedad industrial». Instituto de Estudios Políticos. Madrid, 1975. P. 252.

3. En el caso de Gran Bretaña parece que ha dado lugar a menos problemas por el cuidadoso sistema de organización de las comunicaciones basado en el servicio público independiente del Gobierno. Para el caso de EE.UU. ver D.M. O'BRIEN: «El derecho del público a la información. La Suprema Corte de los E.U.A. y la Primera Enmienda Constitucional». publigrafics, México D.F., 1983.

4. R. Salvador Coderch. «El mercado de las ideas». En: Claves de Razón Práctica, n. ${ }^{\circ} 4$, Madrid, julio-agosto, 1990.

5. Idem. P. 41.

6. Por ejemplo: STC 61/1981, 12/1982, 13/1985, 51/1985, 104/1986, 165/1987, 6/1988, $51 / 1989,9 / 1990,20 / 1990$.

7. M. Carrillo. «Los límites a la libertad de prensa en la Constitución Española de 1978». PPV, Barcelona, 1987. P. 18.

8. En España este límite venía señalado específicamente en el artículo 20 C.E. al referirse a lo dispuesto al art. 18.1 C.E. y que fue desarrollado por la Ley Orgánica 1/1982 de 5 de mayo de protección civil del derecho al honor, a la intimidad personal y familiar y a la propia imagen. Ver: STC 159/1986, 107/1988, 37/1989 y 51/1989 así como la sentencia del tribunal Europeo de Derechos Humanos en el caso Lingens (8-7-1986). Para un enfoque doctrinal ver: M. de la Valgoma. Comentario a la Ley Orgánica de protección civil 
del derecho al honor, a la intimidad personal y familiar y la propia imagen. En: «Anuario de Derechos Humanos», n. ${ }^{\circ}$ 2, Madrid, 1983.

9. Así figura en el artículo 10.1 del Convenio de Roma. Sin embargo hay que ser cauto en la inclusión de esta limitación de la actividad privada como límite a la libertad de expresión. En algunos casos nos encontramos ante un auténtico límite incluible en esta tipología, en otros, cuando interviene el ánimo de lucro, nos encontramos normalmente con un límite a la propiedad privada $0 / y$ a la libertad de creación de empresas.

10. D. López Garrido. «Terrorismo, política y derecho». Alianza, Madrid, 1987. P. 131 y ss.

11. Idem. P. 65 y ss.

12. Idem. P. 194 y 195.

13. Ph. Bilger y B. Prevost. Op. cit. P. 45 y ss. y 76 y ss.

14. J. Delumeau. «El miedo en Occidente». Taurus, Madrid, 1989. P. 432 y ss.

15. En el caso español la articulación interna es incompleta aunque sea de general aplicación el artículo 10.2 de la Constitución sobre normas relativas a derechos fundamentales, libertades y su interpretación de acuerdo con los textos internacionales. Por otra parte todos los textos citados, con la lógica excepción del Pacto de San José, han sido ratificados por España. Ver: Convenio sobre genocidio: BOE n. ${ }^{\circ} 34$ de 8-2-1969, Convenio sobre discriminación racial: BOE n. ${ }^{\circ} 118$ de 17-5-1969, Pacto sobre Derechos Civiles y Políticos: BOE n. ${ }^{\circ} 103$ de 30-4-1977.

16. Ph. Bilger y B. Prevost. Op. cit. P. 47. 